\title{
Caracterização morfofisiológica de bactérias nativas de solos do Cerrado isoladas de nódulos de feijão-caupi
}

\author{
Clicyane Lima de Araújo \\ Régia Maria Reis Gualter * \\ Instituto Federal de Educação, Ciência e Tecnologia do Maranhão, Campus Caxias \\ Gleba Buriti do Paraíso, km 02 - MA, 349, Povoado Lamego - Zona Rural \\ CEP 65.600-992, Caxias - MA, Brasil \\ * Autor para correspondência \\ regiagualter@gmail.com
}

Submetido em 24/08/2016

Aceito para publicação em 16/01/2017

\section{Resumo}

Características como tolerância ao $\mathrm{pH}$, à temperatura, à salinidade e à concentração elevada de alumínio podem ser verificadas em rizóbios nativos oriundos de solos tropicais. Essas particularidades são relevantes em estudos de fixação biológica de nitrogênio, especialmente em Vigna unguiculata L. Walp. (feijão-caupi), uma cultura representativa de suma importância econômica para a agricultura familiar das diferentes regiões brasileiras, especialmente do Norte e Nordeste. Assim, o objetivo deste trabalho foi isolar e caracterizar morfofisiologicamente bactérias nativas de solos do Cerrado leste maranhense, utilizando o feijão-caupi como planta-isca. O estudo foi realizado em Caxias, MA entre os anos de 2014 e 2015. Os isolados foram oriundos de nódulos de feijão-caupi, provenientes de amostras de solos de três áreas diferentes: mata especialmente composta de babaçuais, de cultivos de Manihot esculenta (mandioca) e de Desmanthus virgatus L. (jureminha). Os isolados foram submetidos à caracterização morfológica de suas colônias e a testes fisiológicos como: teste de tolerância às altas temperaturas, à acidez, ao alumínio e às altas salinidades. Os isolados obtidos evidenciaram significativa diversidade morfológica. Os testes fisiológicos demonstraram que a maioria deles é resistente às altas temperaturas, à acidez e ao alumínio tóxico, mas poucos deles são resistentes às altas salinidades.

Palavras-chave: Acidez do solo; Alumínio; Fixação biológica de nitrogênio; Temperatura do solo

\section{Abstract}

Morphophysiological characterization of bacteria native to Cerrado soils, isolated from cowpea nodules. Characteristics such as tolerance to $\mathrm{pH}$, temperature, salinity and high aluminum concentration can be verified in rhizobia native to tropical soils. These particularities are relevant to biological nitrogen fixation studies, such as those about Vigna unguiculata L. Walp. (cowpea), which is of great economic importance to family farmers in different parts of Brazil, especially the North and Northeast regions. The objective of this study was to morphologically and physiologically characterize the native bacteria from Cerrado soils in eastern Maranhão, using the cowpea as plant bait. The study was conducted in Caxias (MA) between 2014 and 2015. The isolates were derived from cowpea nodules sampled from three different areas of soil, especially forest composed of babassu and cultivated Manihot esculenta (cassava) and Desmanthus virgatus L. (jureminha). They were morphologically characterized based on their colonies and the following physiological tests: tolerance to 
high temperatures, acidity, aluminum and high salinity. The isolates showed significant morphological diversity. The physiological tests showed that most of them are resistant to high temperatures, acidity and aluminum toxicity, but only a few are resistant to high salinity.

Key words: Aluminum; Biological Nitrogen Fixation; Soil Acidity; Soil Temperature

\section{Introdução}

A utilização de fertilizantes nitrogenados na agricultura pode ocasionar efeitos negativos ao sistema solo-planta-atmosfera e assim investigações sobre o seu uso e manejo são necessárias tendo em vista os impactos que esses agroquímicos acarretam ao ambiente. Segundo Figueiredo (2012), a utilização da adubação nitrogenada é onerosa, responde pouco às demandas da planta e pode causar danos ecológicos, uma vez que sua perda por lixiviação e escoamento superficial contamina os solos e lençóis freáticos, assim, a estimativa de aproveitamento desses adubos é de cerca de $50 \%$ da quantidade original aplicada.

Uma das alternativas de baixo valor econômico para substituí-los total ou parcialmente é a utilização de um processo conhecido como fixação biológica de nitrogênio (FBN), em que ocorre uma interação simbiótica entre uma planta hospedeira e microrganismos do solo capazes de fixar nitrogênio. Na associação simbiótica entre certos gêneros de bactérias e plantas da família das leguminosas, há formação de nódulos e ambos os organismos são beneficiados, pois a leguminosa fornece fonte de carbono às bactérias e estas por sua vez fornecem o nitrogênio necessário ao desenvolvimento da planta (SILVA, 2012).

A FBN é importante, pois aumenta a eficiência de absorção e de utilização de nutrientes, reduzindo os custos de produção e contribuindo para evitar prejuízos ao meio ambiente. Entre as culturas agrícolas que se beneficiam desse processo, o feijãocaupi (Vigna unguiculata L. Walp.) destaca-se pela rusticidade, além de adaptabilidade às condições de clima e solo, desempenhando um importante papel socioeconômico à agricultura familiar (ZILLI et al., 2006; GUALTER et al., 2011; SILVA et al., 2012) e em lavouras tecnificadas (FREIRE FILHO, 2011).
O feijão-caupi é uma das importantes fontes alimentares e estratégicas de regiões tropicais e subtropicais do mundo, gerando empregos e garantindo o suprimento alimentar de diversas famílias, como as do Norte e Nordeste brasileiros (FREIRE FILHO et al., 2005). Conhecer como ocorre o processo de nodulação e FBN bem como os fatores que o afetam ou o potencializam é uma das formas de aumentar a produtividade da cultura (FRANCO et al., 2002), já que o feijão-caupi, quando bem nodulado por bactérias fixadoras de nitrogênio nodulíferas de leguminosas (BFNNLs), pode dispensar outras fontes de $\mathrm{N}$ e atingir altos níveis de produtividade (RUMJANEK et al., 2005).

Alguns fatores podem dificultar o processo de nodulação e FBN, e para que ocorra uma simbiose eficiente é necessário o conhecimento não só da disponibilidade de $\mathrm{N}$ para a planta, mas também há a necessidade de analisar as características fenotípicas desses microrganismos, pois estas podem auxiliar em estudos de adaptabilidade e tolerância às condições ambientais em que essas associações simbióticas estão inseridas e que afetam a produção agrícola. Entre esses fatores limitantes ao crescimento e desenvolvimento vegetal e à população desses microrganismos no solo podem-se elencar: salinização, diminuição de $\mathrm{pH}$, alta concentração de alumínio e altas temperaturas no solo, características frequentemente presentes em solos tropicais (HUNGRIA; VARGAS, 2000).

A temperatura é um dos fatores que mais pode gerar perdas significativas nessa associação simbiótica entre microrganismo e leguminosa. Em solos tropicais, a temperatura se mostra bastante limitante, pois pode atingir valores superiores a $40^{\circ} \mathrm{C}$, muito acima da considerada ótima para as BFNNLs, que é em torno de $28^{\circ} \mathrm{C}$. Assim, altas temperaturas são prejudiciais ao processo de FBN nos trópicos (VARGAS; HUNGRIA, 1997), além de acarretar a redução do tamanho dos nódulos e da população de BFNNLs. 
Outro fator limitante é a acidez do solo, que é provocada, sobretudo, pela alta concentração de íons $\mathrm{H}+$ e por outros fatores como saturação e toxidade por Al e Mn (RUFINI et al., 2011), solos com pH ácido possuem valores de $\mathrm{pH}$ muito abaixo de $6 . \mathrm{O} \mathrm{pH}$ do solo tanto muito baixo quanto muito alto afeta significativamente a simbiose e a principal consequência causada pela acidez é a deficiência nutricional no solo, com proporções baixas de nutrientes como o fósforo, o cálcio e o magnésio. Em contrapartida, altas taxas de alumínio e manganês provocam redução no desenvolvimento radicular das plantas e na quantidade de microrganismos fixadores de nitrogênio no solo, além de baixar a eficiência das populações remanescente (FIGUEIREDO et al., 2008).

As altas concentrações de sais na zona radicular do solo também é um fator que afeta a interação bactériaplanta. Os sais solúveis mais efetivos no processo de salinização do solo consistem, normalmente, em várias proporções de cátions de cálcio, magnésio, sódio e em ânions cloreto, sulfato, bicarbonato e, às vezes, carbonato. As principais consequências que a alta salinidade pode provocar na absorção e utilização de nutrientes está relacionada com o aumento da pressão osmótica na solução do solo, com a acumulação de certos íons no tecido vegetal, em concentrações tóxicas, e com a diminuição no crescimento do sistema radicular (FAGERIA, 1998).

Apesar da relevância de pesquisas sobre o conhecimento de características peculiares de isolados bacterianos nodulíferos nativos, são escassos os trabalhos em ambientes como o Cerrado maranhense. Nesse sentido, o objetivo deste estudo foi caracterizar morfofisiologicamente bactérias nativas de feijão-caupi oriundas de solos desse ecossistema.

\section{Material e Métodos}

O presente estudo foi desenvolvido no Instituto Federal de Educação, Ciência e Tecnologia do Maranhão, Campus Caxias, localizado na Rodovia MA, 349 - km 02, Gleba Buriti do Paraíso, Povoado Lamego, Zona Rural de Caxias, Maranhão. Caxias é a terceira maior cidade do estado, apresentando as seguintes coordenadas geográficas: $4^{\circ} 51^{\prime}$ de Latitude Sul e $43^{\circ} 21^{\prime}$ de Longitude
Oeste de Greenwich. A altitude fica em torno de $66 \mathrm{~m}$ ao nível do mar, com uma área de $5224 \mathrm{~km}^{2}$, sendo constituída paisagística e fisionomicamente pelo Cerrado, possuindo dois estratos, um arbóreo-arbustivo, e outro, graminoso (NERES; CONCEIÇÃO, 2010).

Os solos de Caxias - MA são classificados como Neossolos Quartzarênicos, caracterizados principalmente por alta acidez, baixos teores de nutrientes e textura arenosa (CONCEIÇÃO et al., 2014). O clima é classificado como tropical semi-úmido, com temperatura mínima de $22,40^{\circ} \mathrm{C}$, máxima de $32,59^{\circ} \mathrm{C}$, média anual de $26,76^{\circ} \mathrm{C}$, segundo classificação de Köppen. As áreas avaliadas foram selecionadas em virtude de duas apresentarem cultivos, além de uma terceira considerada de referência, por se tratar de mata nativa.

A amostragem de solo foi realizada em três áreas distintas, que constituíram os tratamentos avaliados, sendo elas: área de mata (composta notadamente de babaçuais), área de cultivo de Manihot esculenta (mandioca) e área de cultivo de Desmanthus virgatus L. (jureminha). Em cada área, foram coletadas amostras compostas constituídas de 10 amostras simples na profundidade de 0-20 cm. Em seguida, as amostras recém-coletadas foram secas ao ar, destorroadas e passadas em peneira com malha de $5 \mathrm{~mm}$ de abertura. Posteriormente, as amostras de solo foram homogeneizadas e adicionadas a vasos plásticos de $2 \mathrm{~kg}$.

Para a captura das BFNNLs, foi realizado um experimento em casa-de-vegetação, onde os solos anteriormente coletados foram utilizados como fonte de inóculo para as plantas de feijão-caupi. No plantio, utilizou-se a cultivar de feijão-caupi (BRS Guariba) como planta-isca, sendo cultivada em vasos contendo uma proporção de areia esterilizada e solo $(2: 1 ; 200$ g: 100 g). Antes do plantio, realizou-se a desinfecção das sementes do feijão-caupi, imergindo-as em álcool a $100 \%$ por 30 segundos e hipoclorito de sódio a 2,0\% por 3 minutos e 10 lavagens sucessivas com água destilada esterilizada. Em seguida, foram semeadas quatro sementes por vaso. A irrigação foi realizada semanalmente com água destilada esterilizada, e os nutrientes fornecidos foram o fósforo na forma de $\mathrm{P}_{2} \mathrm{O}_{5}$ e o potássio na forma de $\mathrm{KCl}$, aplicados sobre o solo nas doses de 60 e $20 \mathrm{~kg} \cdot \mathrm{ha}^{-1}$, respectivamente, conforme 
recomendado por Melo et al. (2005). Aos 35 dias após o plantio, as plantas de feijão-caupi foram coletadas para análise das seguintes variáveis: número e massa seca de nódulos e massa seca da parte aérea (resultados não apresentados). As raízes foram separadas da parte aérea em corte no ponto de inserção cotiledonar, e os nódulos foram contados, secos em papel absorvente, pesados e guardados. O delineamento experimental foi inteiramente casualizado, sendo três tratamentos e quatro repetições.

Para isolamento dos rizóbios, foram selecionados três nódulos grandes de coloração escura de raízes das plantas de cada tratamento. Esses nódulos foram desinfestados por imersão em álcool a $100 \%$ por 30 segundos e hipoclorito de sódio a $2,0 \%$ por 3 minutos e 10 lavagens sucessivas com água destilada e esterilizada. Posteriormente, os nódulos foram macerados com auxílio de uma pinça e riscados com alça de platina em placa de Petri contendo meio de cultura composto de manitol, extrato de levedura e ágar (YMA), tendo como indicador o corante vermelho congo (VINCENT, 1970). Após esse procedimento, as placas foram incubadas em estufa tipo B.O.D. (Biochemistry Oxigen Demand) a $28^{\circ} \mathrm{C}$ por até três dias, período em que foi visualizado o aparecimento de colônias. Em seguida, as colônias com aspecto arredondado e de coloração clara que não haviam absorvido o corante foram selecionadas e repicadas sucessivamente, sendo semeadas pelo método de esgotamento por estrias, com o auxílio de uma alça de platina no meio YMA 79 com azul de bromotimol até purificação das culturas.

Para caracterização morfológica, utilizou-se uma colônia de cada isolado, em que se verificaram características como: forma (puntiforme, circular, irregular), elevação (plana, convexa, achatada), borda (inteira, ondulada, filamentosa, lobada, denteada), consistência do muco (viscosa, seca, gomosa), produção de muco (pouco, moderado, abundante), tamanho, coloração, tempo de crescimento, alteração do meio de cultura pelas bactérias (COSTA JÚNIOR et al., 2009) e também características fisiológicas tais como a formação de ácido e álcalis (AC: ácida; AL: alcalina; N: neutra) (SILVA et al., 2007). Depois dessa etapa, as culturas foram repicadas novamente em meio YMA e foram colocadas em estufas B.O.D. nas temperaturas de $39^{\circ} \mathrm{C}$, $45^{\circ} \mathrm{C}$ e $50^{\circ} \mathrm{C}$ durante um período de sete dias (SILVA et al., 2007), onde as observações foram realizadas no $2^{\circ}$, $4^{\circ}$ e no $7^{\circ}$ dia.

Os isolados foram nomeados de acordo com a instituição onde foi realizado o estudo, seguido da abreviatura da área de amostragem do solo de onde foram retirados e, por último, pelo número de identificação do croqui experimental, conforme Tabela 1.

TABELA 1: Descrição dos solos amostrados. Caxias - MA, 2014.

\begin{tabular}{cc}
\hline Isolado & Utilização da área/solo \\
\hline IFMA-MT1 & Mata \\
IFMA-JR2 & Jureminha \\
IFMA-MD3 & Mandioca \\
IFMA-MD4 & Mandioca \\
IFMA-JR5 & Jureminha \\
IFMA-MT6 & Mata \\
IFMA-JR7 & Jureminha \\
IFMA-MD9 & Mandioca \\
IFMA-MD10 & Mandioca \\
IFMA-MT11 & Mata \\
IFMA-JR12 & Jureminha \\
\hline
\end{tabular}

Os isolados foram crescidos em tubos de ensaio contendo meio de cultura YM líquido durante três dias a $28^{\circ} \mathrm{C}$ em B.O.D. Em seguida, foram retiradas alíquotas de $0,1 \mathrm{~mL}$ de cada tubo e semeadas com o auxílio de alças de Drigalski em placas de Petri contendo concentrações de $\mathrm{NaCl}\left(25,37,5\right.$ e 50 g. $\left.\mathrm{L}^{-1}\right)$, contidas no meio de cultura YMA, sendo distribuídas inteiramente ao acaso, com três repetições. Após essa etapa, os isolados foram colocados em B.O.D. durante um período de 21 dias, sendo as observações realizadas a cada sete dias (MEDEIROS et al., 2007).

$\mathrm{Na}$ avaliação de tolerância à acidez e ao alumínio tóxico, os isolados foram transferidos para o meio YMA, sendo avaliados em $\mathrm{pH} 4,5, \mathrm{pH} 4,5+6,0$ cmolc Al. $\mathrm{L}^{-1}$ e $\mathrm{pH}$ 6,5. A fonte de alumínio utilizada foi $\mathrm{AlCl}_{3}$. Para verificar a alteração do $\mathrm{pH}$ do meio pelas bactérias, foram utilizados os indicadores verde de bromocresol (20 mL.L ${ }^{-1}$ ) nos meios com pH 4,5, pH 4,5 + 6,0 cmolc Al. $\mathrm{L}^{-1}$, e azul de bromotimol $\left(5 \mathrm{~mL} . \mathrm{L}^{-1}\right)$ no meio com pH 6,5. As bactérias foram mantidas em estufa B.O.D. 
à temperatura de $28^{\circ} \mathrm{C}$. As placas foram observadas a cada três dias, por um período de 18 dias, e os resultados foram estabelecidos de acordo com o desenvolvimento das colônias nas quatro zonas da placa, possuindo desenvolvimento de 0 (sem crescimento visível na placa) a 4 (máximo crescimento em todas as zonas).

Assim, a classificação dos isolados foram: não tolerantes (sem crescimento nas quatro zonas), sensíveis (crescimento em uma ou duas zonas), medianamente tolerantes (crescimento em três zonas) ou tolerantes (crescimento em quatro zonas) (HARA; OLIVEIRA, 2004). Foram utilizadas duas placas para cada isolado e cada placa foi marcada ao meio e na metade dela continha uma repetição, sendo ao todo quatro repetições por placa de Petri. Para a inoculação foi utilizado o método adaptado de Oliveira e Magalhães (1999), como ilustra a Figura 1, em que os isolados foram riscados em quatro zonas, sendo elas 1, 2, 3 e 4, e aqueles que cresceram em todas as zonas foram considerados tolerantes à acidez.

FIGURA 1: Ilustração do método de inoculação. Adaptado de Oliveira e Magalhães (1999).

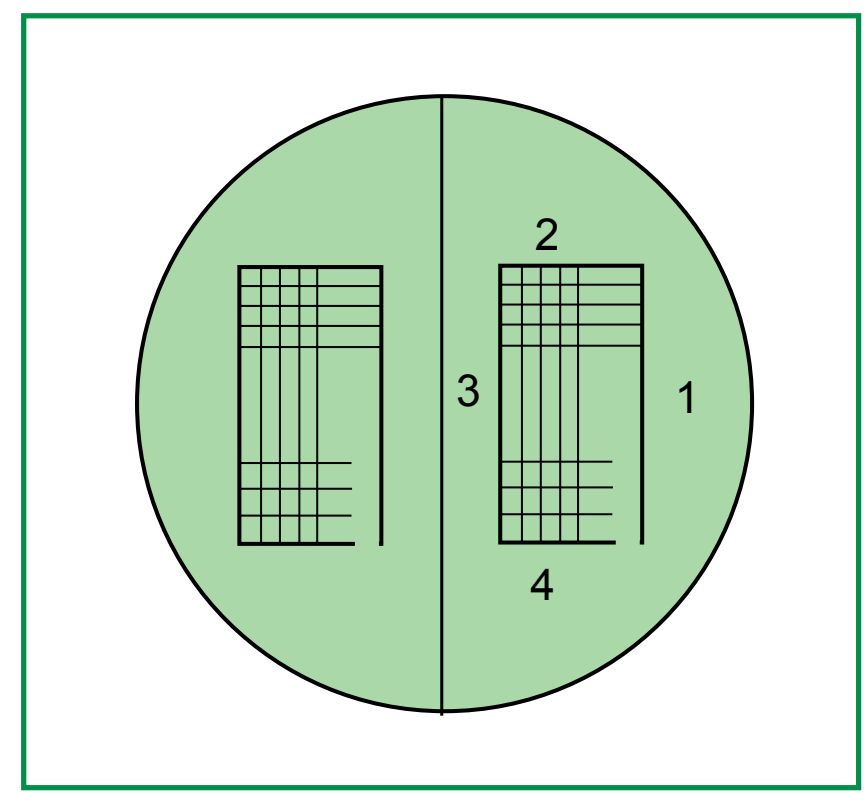

\section{Resultados}

Com o isolamento das bactérias nativas nodulíferas em meio de cultura (YMA) obteve-se um número de 11 isolados, conseguindo-se um isolado por cada tratamento.
A caracterização cultural das colônias desses isolados demonstraram que, em relação à alteração do meio de cultura, oito (73\%) acidificaram (IFMA-JR2, IFMAMD3, IFMA-MD4, IFMA-JR5, IFMA-MT6, IFMAJR7, IFMA-MD9 e IFMA-MD10) e três alcalinizaram (27\%) (IFMA-MT1, IFMA-MT11 e IFMA-JR12), sendo que todos eles (100\%) (IFMA-MT1, IFMA-JR2, IFMA-MD3, IFMA-MD4, IFMA-JR5, IFMA-MT6, IFMA-JR7, IFMA-MD9, IFMA-MD10, IFMA-MT11 e IFMA-JR12) apresentaram crescimento muito rápido, no período de um dia. Quanto ao tamanho, cinco (45\%) deles apresentaram tamanho $\mathrm{T} \leq 1,5$ (IFMA-MT1, IFMA-MD3, IFMA-MT6, IFMA-MD9 e IFMA-JR12), outros cinco (45\%) apresentaram $T \geq 2$ e $\leq 4$ (IFMAMD4, IFMA-JR5, IFMA-JR7, IFMA-MD10, IFMAMT11) e apenas $1(10 \%)$ isolado apresentou $\mathrm{T}=5$, (IFMA-JR2). Em relação à coloração das colônias, oito (73\%) apresentaram-se amarelas (IFMA-JR2, IFMAMD3, IFMA-MD4, IFMA-JR5, IFMA-MT6, IFMAJR7, IFMA-MD9 e IFMA-MD10) e três (27\%) foram brancas (IFMA-MT1, IFMA-MT11 e IFMA-JR12). Já quanto à produção de muco, quatro isolados $(36,4 \%)$ o produziram de forma moderada (IFMA-JR2, IFMAMD3, IFMA-JR5, IFMA-JR7), três (27,2\%), de forma abundante (IFMA-MD4, IFMA-MD9, IFMA-MD10) e os outros quatro $(36,4 \%)$ produziram pouco muco (IFMA-MT1, IFMA-MT6 e IFMA-MT11, IFMA-JR12). $\mathrm{Na}$ consistência do muco, quatro $(36,4 \%)$ foram secas (IFMA-MT1, IFMA-MT6, IFMA-MT11 e IFMA-JR12), cinco $(45,5 \%)$ gomosas (IFMA-JR2, IFMA-MD4, IFMA-JR7, IFMA-MD9, IFMA-MD10) e duas $(18,1 \%)$ viscosas (IFMA-MD3, IFMA-JR5). Verificou-se que as formas das colônias foram as seguintes: três $(27 \%)$ circulares (IFMA-MT1, IFMA-MD4 e IFMA-MT6) e oito $(73 \%)$ irregulares (IFMA-JR2, IFMA-MD3, IFMA-JR5, IFMA-JR7, IFMA-MD9, IFMA-MD10, IFMA-MT11, IFMA-JR12). Quanto às bordas das colônias, obtiveram-se quatro $(36,4 \%)$ isolados com borda ondulada (IFMA-JR2, IFMA-MD3, IFMA-MD9 e IFMA-MT11), quatro (36,4\%) com borda denteada (IFMA-JR5, IFMA-JR7, IFMA-MD10 e IFMA-JR12) e três $(27,2 \%)$ com borda inteira (IFMA-MT1, IFMAMD4 e IFMA-MT6). Observando o detalhe óptico, oito (73\%) foram opacas (IFMA-MT1, IFMA-JR2, IFMAMD3, IFMA-MD4, IFMA-JR5, IFMA-JR7, IFMA- 
MD9 e IFMA-MD10) e três (27\%) foram translúcidas (IFMA-MT6, IFMA-MT11, IFMA-JR12). Em relação à elevação das colônias, cinco isolados $(45,6 \%)$ apresentaram elevação plana (IFMA-MT1, IFMA-JR5, IFMA-MT6, IFMA-MT11, IFMA-JR12), três (27,2\%), do tipo lente (IFMA-JR2, IFMA-MD9 e IFMA-MD10) e os outros três $(27,2 \%)$, convexa (IFMA-MD3, IFMAMD4 e IFMA-JR7) (Tabela 2).

No teste de tolerância à temperatura, dos 11 isolados analisados, todos $(100 \%)$ apresentaram rápido crescimento à temperatura de $38^{\circ} \mathrm{C}$, considerada uma temperatura estressante. Porém, nas temperaturas de $50^{\circ} \mathrm{C}$ e $45^{\circ} \mathrm{C}$, apenas nove foram resistentes, sendo os isolados IFMA-MT11 e IFMA-JR12 os que não toleraram essas temperaturas (Tabela 3 ).

Os resultados encontrados nas avaliações relacionadas ao crescimento microbiano em diferentes concentrações salinas $\left(25,37,5\right.$ e 50 g.L $\mathrm{L}^{-1}$ de $\left.\mathrm{NaCl}\right)$ estão apresentados na Figura 2. A partir da análise desses resultados, observou-se que os isolados IFMA-MT1, IFMA-MD4, IFMA-JR5, IFMA-MD9 e IFMA-JR12 apresentaram máximo crescimento na concentração salina de 25 g.L $\mathrm{L}^{-1}$ de $\mathrm{NaCl}$, sendo que os isolados IFMA-MD4 e IFMA-JR12 foram os únicos que

TABELA 2: Caracterização cultural de bactérias nodulíferas de leguminosas. Caxias - MA, 2015.

\begin{tabular}{|c|c|c|c|c|c|c|c|c|c|c|}
\hline \multirow{2}{*}{ Isolado } & \multicolumn{10}{|c|}{ Características } \\
\hline & AMC & TC & $T(\mathrm{~mm})$ & $\mathbf{C}$ & PM & $\mathbf{C M}$ & $\mathbf{F}$ & B & DO & $\mathbf{E}$ \\
\hline IFMA-MT1 & $\mathrm{Al}$ & MR & 1 & B & $\mathrm{P}$ & $\mathrm{S}$ & $\mathrm{C}$ & In & Op & Pl \\
\hline IFMA-JR2 & Ac & MR & 5 & $\mathrm{~A}$ & $\mathrm{M}$ & G & I & $\mathrm{O}$ & Op & $\mathrm{Lt}$ \\
\hline IFMA-MD3 & Ac & MR & 1,5 & A & $\mathrm{M}$ & V & I & $\mathrm{O}$ & Op & $\mathrm{Cv}$ \\
\hline IFMA-MD4 & Ac & MR & 2 & A & $\mathrm{Ab}$ & G & $\mathrm{C}$ & In & $\mathrm{Op}$ & $\mathrm{Cv}$ \\
\hline IFMA-JR5 & Ac & MR & 4 & A & $\mathrm{M}$ & V & I & $\mathrm{D}$ & $\mathrm{Op}$ & $\mathrm{Pl}$ \\
\hline IFMA-MT6 & Ac & MR & 1,5 & A & $\mathrm{P}$ & $\mathrm{S}$ & $\mathrm{C}$ & In & $\mathrm{Tl}$ & $\mathrm{Pl}$ \\
\hline IFMA-JR7 & Ac & MR & 2 & A & $\mathrm{M}$ & G & I & $\mathrm{D}$ & Op & $\mathrm{Cv}$ \\
\hline IFMA-MD9 & Ac & MR & 1,5 & A & $\mathrm{Ab}$ & G & I & $\mathrm{O}$ & Op & $\mathrm{Lt}$ \\
\hline IFMA-MD10 & Ac & MR & 3 & A & $\mathrm{Ab}$ & $\mathrm{G}$ & I & $\mathrm{D}$ & Op & $\mathrm{Lt}$ \\
\hline IFMA-MT11 & $\mathrm{Al}$ & MR & 4 & B & $\mathrm{P}$ & S & I & $\mathrm{O}$ & $\mathrm{Tl}$ & $\mathrm{Pl}$ \\
\hline IFMA-JR12 & $\mathrm{Al}$ & MR & 1,5 & B & $\mathrm{P}$ & $\mathrm{S}$ & I & $\mathrm{D}$ & $\mathrm{Tl}$ & $\mathrm{Pl}$ \\
\hline
\end{tabular}

Alteração do meio de cultura (AMC): Al - Alcalino, Ac - Ácido. Tempo de crescimento (TC): M.R - muito rápido, $\mathrm{R}$ - rápido, $\mathrm{L}$ - lento. Tamanho (T), Coloração (C): A - amarela, B - branca. Produção de muco (PM): P - pouca, M - moderada, Ab - Abundante. Consistência do muco (CM): S - seca, G - gomosa e V - viscosa. Forma da colônia (F): C - circular, I - irregular. Borda (B): In - inteira, O - ondulada, D - denteada. Detalhe Óptico (DO): Op - opaca, Tl - translúcida e Elevação (E): Pl - plana, L - lente, Cv - convexa

TABELA 3: Teste de tolerância de bactérias nodulíferas de leguminosas a diferentes temperaturas. Caxias - MA, 2015.

\begin{tabular}{cccc}
\hline Isolado & & Temperaturas & \\
\cline { 2 - 4 } & $\mathbf{3 8}^{\mathbf{0}} \mathbf{C}$ & $\mathbf{4 5}^{\mathbf{0}} \mathbf{C}$ & + \\
\hline IFMA-MT1 & + & + & + \\
IFMA-JR2 & + & + & + \\
IFMA-MD3 & + & + & + \\
IFMA-MD4 & + & + & + \\
IFMA-JR5 & + & + & + \\
IFMA-MT6 & + & + & + \\
IFMA-JR7 & + & + & + \\
IFMA-MD9 & + & + & + \\
IFMA-MD10 & + & - & - \\
IFMA-MT11 & + & - \\
IFMA-JR12 & + & - & + \\
\hline
\end{tabular}

Os isolados tolerantes foram considerados positivos $(+)$ e, os não tolerantes, negativos (-). 
tiveram crescimento em todas as concentrações salinas analisadas, mas apresentando pouco crescimento na concentração salina de 50 g.L. $\mathrm{L}^{-1}$. O isolado IFMA-MD4 também teve destaque na concentração de 37,5 g.L $\mathrm{L}^{-1}$ por apresentar máximo crescimento nesse valor de salinidade, considerado, assim, tolerante. Há ainda os isolados que apresentaram um baixo índice de crescimento na concentração de 25 g.L. $\mathrm{L}^{-1}$ de $\mathrm{NaCl}$ (IFMAMD3, IFMA-MT6 e IFMA-MT11) e aqueles com pouco crescimento na concentração de 37,5 g. $\mathrm{L}^{-1}$ de $\mathrm{NaCl}$, (IFMA-MD3, IFMA-JR5 e IFMA-JR12). Os isolados IFMA-JR2, IFMA-JR7 e IFMA-MD10 não cresceram nos valores de salinidade avaliados, sendo considerados não tolerantes. No geral, verificou-se um número significativo de isolados tolerantes $(45,5 \%)$ a 25 g.L.de $\mathrm{NaCl}$, e $(27,3 \%)$ de isolados com pouco crescimento em alguma das concentrações de $\mathrm{NaCl}$ analisadas. Os demais isolados (27,3\%) não apresentaram crescimento nos valores de salinidade testados (Figura 2).

No teste de tolerância à acidez e ao alumínio tóxico, verificou-se que dos isolados submetidos ao $\mathrm{pH} \mathrm{4,5}$ com verde de bromocresol apenas três (27\%) (IFMAMT1, IFMA-MD4, IFMA-JR5) apresentaram máximo desenvolvimento em toda a zona, sendo tolerantes a esse valor de $\mathrm{pH}$ ao $3^{\circ}$ dia de incubação. $\mathrm{O}$ isolado IFMAMD4 apresentou alta produção de muco e, nos demais isolados, essa produção foi escassa. Nesse mesmo valor de $\mathrm{pH}$, dois isolados (18\%) foram sensíveis, apresentando crescimento em uma zona (IFMA-JR2, IFMA-MD3) e os outros seis isolados (55\%) não apresentaram crescimento nas zonas até o $18^{\circ}$ dia, sendo considerados não tolerantes. No pH 6,5 com azul de bromotimol, todos os isolados (100\%) apresentaram crescimento em todas as zonas até o 3 o dia de incubação. Os isolados IFMA-MT1, IFMA-JR2, IFMA-MD3, IFMA-MD4, IFMA-MT6, IFMA-JR7, IFMA-MD9 e IFMA-MD10, correspondentes a $73 \%$, acidificaram o meio de cultura e o restante (27\%) não apresentou alteração do meio. No pH 4,5 com 2 cmolc. $\mathrm{L}^{-1}$ de $\mathrm{AlCl}_{3}$, observaram-se quatro isolados $(36 \%)$ tolerantes (IFMA-MT1, IFMAJR2, IFMA-MD3 e IFMA-JR12) e dois isolados (18\%) sensíveis (IFMA-MT6 e IFMA-JR7), sendo que IFMAMT6 apresentou crescimento total em duas zonas, e o IFMA-JR7, em apenas uma zona. Nesse pH, 46\% dos isolados não foram tolerantes. De modo geral, não houve variação do crescimento dos isolados nas zonas entre o $3^{\circ}$ e o $18^{\circ}$ dia de incubação em todos os valores de $\mathrm{pH}$. Apenas o isolado IFMA-MD4, no pH 4,5 (sem

FIGURA 2: Padrões de crescimento de bactérias nativas nodulíferas de feijão-caupi expostas a diferentes concentrações de $\mathrm{NaCl}$ (g/L) em meio YMA. Caxias - MA, 2015. * $0=$ sem crescimento; $1=$ pouco crescimento; $2=$ crescimento razoável, porém com distribuição heterogênea na placa; 3 = crescimento máximo.

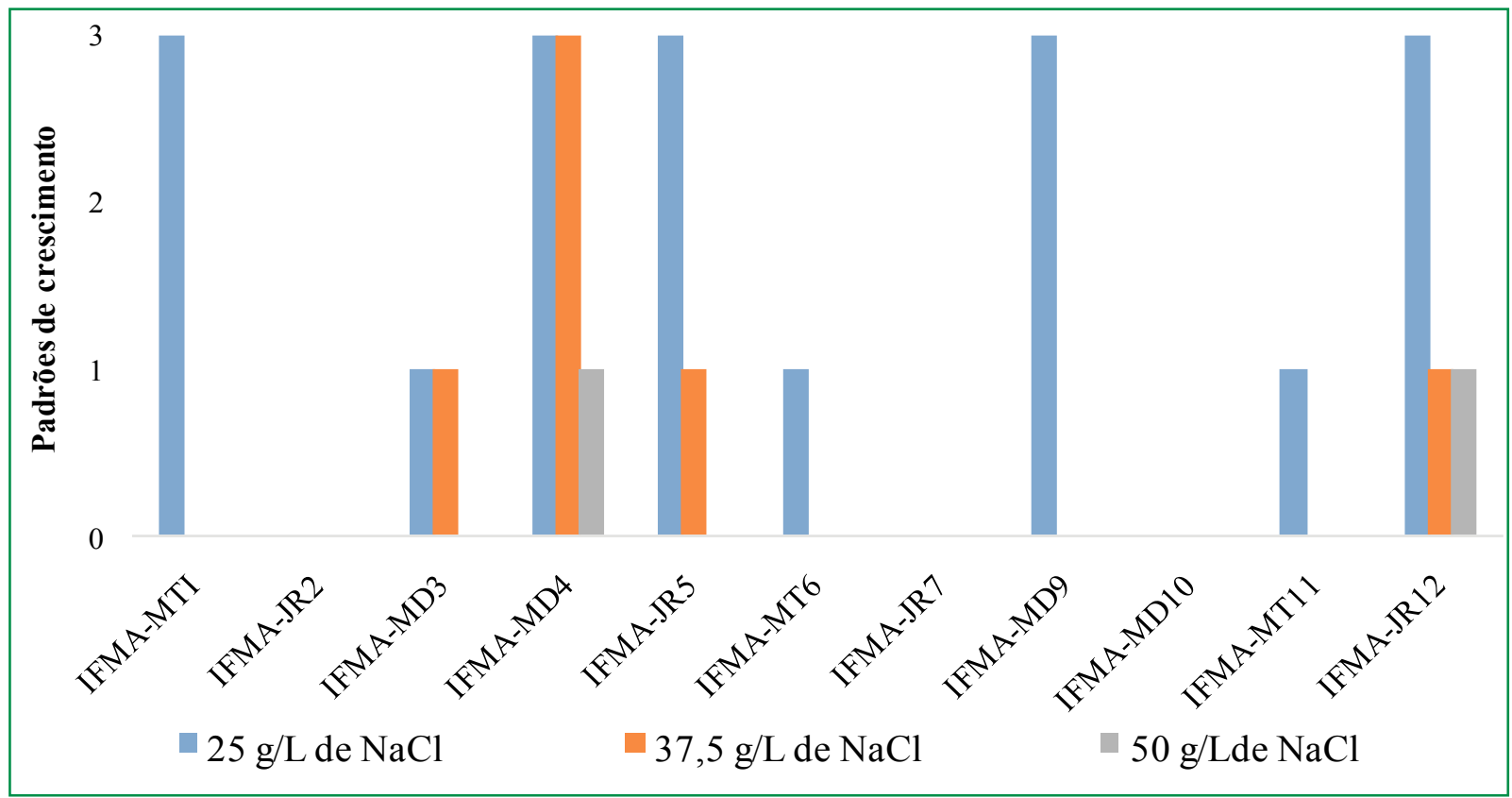


alumínio) e 6,5, teve abundante produção de muco, já os outros isolados, cerca de $91 \%$ demonstraram moderada produção de muco no $\mathrm{pH}$ 6,5 e escassa no $\mathrm{pH}$ 4,5 (sem alumínio), como ilustra a Tabela 4 . Em pH 4,5 com alumínio, $100 \%$ dos isolados tolerantes apresentaram produção escassa de muco, sendo que os isolados IFMAMD4, IFMA-JR5, IFMA-MD9, IFMA-MD10 e IFMAMT11 não foram considerados tolerantes, pois, apesar de apresentaram crescimento de colônias em partes das zonas ou fora delas, não apresentaram crescimento em toda as zonas (Tabela 4).

\section{Discussão}

De acordo com os dados apresentados na Tabela 2, verifica-se que os isolados foram classificados em dois grupos, sendo que o primeiro apresentou oito isolados (IFMA-JR2, IFMA-MD3, IFMA-MD4, IFMA-JR5, IFMA-MT6, IFMA-JR7, IFMA-MD9 e IFMA-MD10) que acidificaram e apresentaram coloração amarela, com maiores tamanhos $T \geq 1,5$ e $\leq 5$ e grande variação na produção e consistência do muco, indo desde moderada/ gomosa (25\%), abundante/gomosa (27\%), moderada/ viscosa $(25 \%)$ à pouca produção de muco e consistência seca (12,5\%), sendo esses isolados os que apresentaram menor quantidade de forma circular (25\%), borda inteira $(25 \%)$ e elevação plana das colônias $(25 \%)$, possuindo o menor índice de detalhe óptico translúcido da colônia (12,5\%). Já o segundo grupo apresentou os três isolados (IFMA-MT1, IFMA-MT11 e IFMA-JR12) que alcalinizaram o meio de cultura, apresentando colônias de menores tamanhos $\mathrm{T} \geq 1 \mathrm{e} \leq 4$, com coloração branca, pouca produção de muco, demonstrando consistência seca e elevação da colônia plana (100\%), apenas apresentaram variação quanto à forma e à borda da colônia, sendo $50 \%$ circular inteira, $25 \%$ irregular denteada e $25 \%$ irregular ondulada. Verificou-se que dos três isolados que alcalinizaram o meio de cultura, dois deles (IFMA-MT1 e IFMA-MT11) são provenientes do tratamento do solo da área de mata e um (IFMA-JR12) da área de Desmanthus virgatus L. Esses resultados apresentaram variações das características das colônias, demonstrando a grande diversidade morfológica dessas populações bacterianas, conforme afirmam Moreira et al. (1998), que destacam que as principais características que indicam a presença de diferentes gêneros de BFNNLs são o tempo de crescimento e a modificação do pH do meio de cultura. Cassetari (2010), analisando a diversidade de bactérias nodulíferas de leguminosas em solos da Amazônia, encontrou 90\% de isolados de crescimento rápido e $82 \%$ acidificantes do meio de cultura, apresentando coloração amarela, branca e creme, os mesmo valores obtidos por Melloni et al. (2006), que constataram uma similaridade dos isolados obtidos com BFNNLs do gênero Rhizobium e Sinorhizobium, pois estas apresentam, comumente, crescimento rápido e caráter acidificante, os autores também afirmam que bactérias de crescimento lento e caráter alcalinizante são

TABELA 4: Teste de tolerância de bactérias nodulíferas de leguminosas à acidez e ao alumínio tóxico. Caxias - MA, 2015.

\begin{tabular}{|c|c|c|c|c|c|c|c|c|c|}
\hline \multirow{3}{*}{ Isolados } & \multicolumn{3}{|c|}{ 3- dia } & \multicolumn{3}{|c|}{ 6o dia } & \multicolumn{3}{|c|}{$18^{\circ}$ dia } \\
\hline & pH & pH & pH 4,5 & pH & pH & pH 4,5 & pH & pH & $\mathrm{pH} 4,5$ \\
\hline & 4,5 & 6,5 & Al & 4,5 & 6,5 & Al & 4,5 & 6,5 & Al \\
\hline IFMA-MT1 & 4 & 4 & 4 & 4 & 4 & 4 & 4 & 4 & 4 \\
\hline IFMA-JR2 & 1 & 4 & 4 & 1 & 4 & 4 & 1 & 4 & 4 \\
\hline IFMA-MD3 & 1 & 4 & 4 & 1 & 4 & 4 & 1 & 4 & 4 \\
\hline IFMA-MD4 & 4 & 4 & 0 & 4 & 4 & 0 & 4 & 4 & 0 \\
\hline IFMA-JR5 & 4 & 4 & 0 & 4 & 4 & 0 & 4 & 4 & 0 \\
\hline IFMA-MT6 & 0 & 4 & 2 & 0 & 4 & 2 & 0 & 4 & 2 \\
\hline IFMA-JR7 & 0 & 4 & 1 & 0 & 4 & 1 & 0 & 4 & 1 \\
\hline IFMA-MD9 & 0 & 4 & 0 & 0 & 4 & 0 & 0 & 4 & 0 \\
\hline IFMA-MD10 & 0 & 4 & 0 & 0 & 4 & 0 & 0 & 4 & 0 \\
\hline IFMA-MT11 & 0 & 4 & 0 & 0 & 4 & 0 & 0 & 4 & 0 \\
\hline IFMA-JR12 & 0 & 4 & 4 & 0 & 4 & 4 & 0 & 4 & 4 \\
\hline
\end{tabular}

0 = não tolerantes, 1 e 2 = sensíveis, 3 = medianamente tolerantes e 4 = tolerantes. Adaptada de Hara e Oliveira (2005). 
encontradas no gênero Bradyrhizobium. Já Moreira e Siqueira (2006) afirmam que as bactérias de crescimento rápido e alcalinizante são frequentemente encontradas no gênero Azorhizobium. Sousa et al. (2014), analisando características morfológicas de bactérias do semiárido isoladas de nódulos de feijão-caupi, encontraram predominância de isolados de crescimento lento e alcalinizantes, com coloração das colônias branca e diâmetro $>1 \mathrm{~mm}$, resultados contrários aos encontrados nesta pesquisa. Sobre isso, Ruiz-Díez et al. (2012) afirmam que o tipo de solo influencia nas características de BFNNLs.

Em relação à Tabela 3, a literatura apresenta que de modo geral os isolados de regiões tropicais são bem resistentes as altas temperaturas, como se observa no presente trabalho. Esses resultados também foram verificados por Sousa et al. (2014) que analisando as características de bactérias nativas de solo do semiárido isoladas de nódulos de feijão-caupi, encontraram um grande índice de bactérias resistentes as temperaturas de $39,41,43$ e $45^{\circ} \mathrm{C}$. Boukhatem et al. (2012), em seu estudo sobre caracterização e diversidade de um determinado grupo de rizóbios em associação simbiótica com acácias nativas e introduzidas em regiões áridas e semi-áridas na Argélia, encontraram bactérias que cresceram a $50^{\circ} \mathrm{C}$.

Avaliando-se os resultados da Figura 2, a concentração de 25 g.L $\mathrm{L}^{-1}$ de $\mathrm{NaCl}$ é considerada alta para rizóbios, podendo comprometer muitos dos seus processos fisiológicos. Contudo, aquelas que são tolerantes a esse fator apresentam mecanismos que estão relacionados à produção de muco, pois este envolve as células bacterianas conferindo-lhes resistência ao efeito osmótico. Nóbrega et al. (2004), estudando o grau de tolerância de bactérias a diferentes concentrações de $\mathrm{NaCl}$, encontraram muitos isolados tolerantes a 30 g.L${ }^{1}$ de $\mathrm{NaCl}$ e um isolado tolerante a 50 g.L $\mathrm{L}^{-1}$ de $\mathrm{NaCl}$. Odee et al. (1997) afirmam que a capacidade de crescer em concentrações mais altas de $\mathrm{NaCl}$ é observada geralmente para estirpes de crescimento rápido, devido à maior produção de polissacarídeos extracelulares que envolvem as células bacterianas, diminuindo o contato com o meio e proporcionando maior resistência da célula ao efeito osmótico.
$\mathrm{Na}$ Tabela 4, observa-se que apenas um isolado foi tolerante aos três valores de $\mathrm{pH}$ testados, resultado divergente de Chagas Júnior et al. (2009), que encontraram grande porcentagem de isolados resistentes a todos esses valores de $\mathrm{pH}$; mas em relação à quantidade de isolados que acidificaram o meio com pH 6,5 e não modificaram o pH 4,5 (sem alumínio) encontraram alta porcentagem, o mesmo observado nesta pesquisa. Em relação à quantidade de bactérias tolerantes, Hara e Oliveira (2005) encontraram baixo percentual de isolados provenientes de solos ácidos resistentes à acidez, $25 \%$ do total avaliado. Sobre isso, Aarons e Graham (1991) afirmam que a acidez pode afetar o crescimento bacteriano, pois em meio ácido há uma diminuição da síntese de proteínas pelas bactérias, além disso, alguns dos seus processos citoplasmáticos são sensíveis à acidez. Nesta pesquisa a acidez foi mais limitante ao crescimento dos microrganismos do que o alumínio, resultado contrário ao de Hara e Oliveira (2005). A produção de muco e a capacidade de acidificar, segundo Hungria et al. (1994) e Coutinho et al. (1999), estão relacionadas ao mecanismo envolvido no processo de adaptação e sobrevivência das bactérias às diferentes condições do meio em que vivem.

\section{Agradecimentos}

As autoras agradecem ao Instituto Federal de Educação, Ciência e Tecnologia do Maranhão pela infraestrutura, financiamento e concessão de bolsa de iniciação tecnológica à primeira autora.

\section{Referências}

AARONS, S. R.; GRAHAM, P. H. Response of Rhizobium leguminosarum bv phaseoli to acidity. Plant and Soil, New York, v. 134, p. 145-151, 1991.

BOUKHATEM, Z. F.; DOMERGUE, O.; BEKKI, A.; MERABET, C.; LAJUDIE, P.; GALIANA, A. Symbiotic characterization and diversity of rhizobia associated with native and introduced acacias in arid and semi-arid regions in Algeria. FEMS, Microbiology Ecology, New York, v. 80, p. 534-547, 2012.

CASSETARI, A. de S. Diversidade de bactérias diazotróficas nodulíferas na Mata Atlântica. 2010. 98 f. Dissertação (Mestrado em Agronomia-Ciências do Solo e Nutrição de Plantas) Universidade de São Paulo, Piracicaba. 2010. 
CHAGAS JUNIOR, A. F.; OLIVEIRA, L. A. de.; OLIVEIRA, A. N. de. Tolerância à acidez e alumínio tóxico por isolados de rizóbios de solos no Amazonas, Brasil. Acta Amazonica, Manaus, v. 39, n. 2, p. 467-470, 2009.

CONCEIÇÃO, G. M.; RUGGIERI, A. C.; SILVA, W. L. Propriedades químicas de um neossolo quartzarênico, Maranhão, Brasil. Agrarian Academy, Goiânia, v. 1, p. 347-353, 2014.

COSTA JÚNIOR, R. C.; SILVA, L. D. A.; OLIVEIRA, A. V.; SOUSA, C. A.; COUTINHO, A. E.; COSTA, A. L.; JUNIOR, M. A. L. Isolamento e caracterização morfológica de bactérias em nódulos de leguminosas forrageiras. In: JORNADA DE ENSINO, PESQUISA e EXTENSÃO DA UFRPE, 9, 2009, Recife. Resumos... Recife: UFRPE, 2009. Disponível em: <http://www. eventosufrpe.com.br/jepex2009/cd/resumos/R1291-1.pdf. $>$.

COUTINHO, H. L. C.; OLIVEIRA, V. M.; MANFIO, G. P.; ROSADO, A. S. Evaluating the microbial diversity of soil samples: methodological innovations. Anais Academia Brasileira de Ciências, São Paulo, v. 71, p. 491-503, 1999.

FAGERIA, N. K. Otimização da eficiência nutricional na produção das culturas. Revista Brasileira de Engenharia Agrícola Ambiental, Campina Grande, v. 2, p. 6-16, 1998.

FIGUEIREDO, M. A. Inoculação com Rhizobium spp. e adubações nitrogenada e molíbidica no feijoeiro-comum. 2012. 99 f. Dissertação (Mestrado em Produção Vegetal) - Universidade Federal de Lavras, Lavras. 2012.

FIGUEIREDO, M. V. B.; LIRA JUNIOR, M. A.; ARAÚJO, A. S. F.; MARTINEZ, C. R. Fatores bióticos e abióticos à fixação biológica de $\mathrm{N}_{2}$. In: FIGUEIREDO, M. V. B.; BURITY, H. A.; STAMFORD, N. P.; SANTOS, C. E. R. S. (Ed.). Microrganismos e agrobiodiversidade: o novo desafio para agricultura. Guaíba: AgroLivros, 2008. p. 43-68.

FRANCO, M. C.; CASSINI, S. T. A; OLIVEIRA, V. R.; VIEIRA, C.; TSAI, S. M. Nodulação em cultivares de feijão dos conjuntos gênicos andino e meso-americano. Pesquisa Agropecuária Brasileira, Brasília, v. 37, n. 8, p. 1145-1150, 2002.

FREIRE FILHO, F. R. Feijão-caupi no Brasil: produção, melhoramento genético, avanços e desafios. Teresina: Embrapa Meio-Norte, 2011. 84 p.

FREIRE FILHO, F. R.; LIMA, J. A. de A.; RIBEIRO, V. Q. (Ed.). Feijão-caupi: avanços tecnológicos. Brasília: Embrapa Informação Tecnológica; Teresina: Embrapa Meio-Norte, 2005. 519 p.

GUALTER, R. M. R.; BODDEY, R. M.; RUMJANEK, N. G.; FREITAS, A. C. R. de; XAVIER, G. R. Eficiência agronômica de estirpes de rizóbio em feijão-caupi cultivado na região da Pré-Amazônia maranhense. Pesquisa Agropecuária Brasileira, Brasília, v. 46, p. 303-308, 2011.

HARA, F. A. S.; OLIVEIRA, L. A. Características fisiológicas e ecológicas de isolados de rizóbios oriundos de solos ácidos e álicos de Presidente Figueiredo, Amazonas. Acta Amazonica, Manaus, v. 34, n. 2, p. 343-357, 2004.

HARA, F. A. S.; OLIVEIRA, L. A. Características fisiológicas e ecológicas de isolados de rizóbios oriundos de solos ácidos de Iranduba, Amazonas. Pesquisa Agropecuária Brasileira, Brasília, v. 40, n. 7, p. 667-672, 2005.

HUNGRIA, M.; VARGAS, M. A. T. Environmental factors affecting N2 fixation in grain legumes in the tropics, with an emphasis on Brazil. Field Crops Research, Weigang, v. 65, p. 151-164, 2000.
HUNGRIA, M.; VARGAS, M. A. T.; SUHET, A. R.; PERES, J. R. R. Fixação biológica do nitrogênio na soja. In: ARAUJO, R. S.; HUNGRIA, M (Ed.). Microrganismos de importância agrícola. Brasília: EMBRAPASPI, 1994. p. 9-89.

MEDEIROS, E. V.; SILVA, K. J. P.; MARTINS, C. M.; BORGES, W. L. Tolerância de bactérias fixadoras de nitrogênio provenientes de municípios do Rio Grande do Norte à temperatura e salinidade. Revista de Biologia e Ciências da Terra, Campina Grande, v. 7, n. 2, p. 160-168, 2007.

MELLONI, R.; MOREIRA, F. M. S.; NÓBREGA, R. S. A.; SIQUEIRA, J. O. Eficiência e diversidade fenotípica de bactérias que nodulam caupi [Vigna unguiculata (1.) Walp] e feijoeiro (Phaseolus vulgaris L.) em solos de mineração de bauxita em reabilitação. Revista Brasileira de Ciência do Solo, Viçosa, v. 30, p. 235-246, 2006.

MElo, F. de B.; CARDoso, M. J.; SAlviano, A. A. C. Fertilidade do solo e adubação. In: FREIRE FILHO, F. R.; LIMA, J. A. de A.; RIBEIRO, V. Q. (Ed.). Feijão-caupi: avanços tecnológicos. Brasília: Embrapa Informação Tecnológica, 2005. p. 28-92.

MOREIRA, F. M. S.; HAUKKA, K.; YOUNG, J. P. W. Biodiversity of rhizobia isolated from a wide range of forest legumes in Brasil. Molecular Ecology, Amsterdam, v. 7, p. 889-895, 1998.

MOREIRA, F. M. S.; SIQUEIRA, J. O. Microbiologia e bioquímica do solo. 2 ed. Lavras: UFLA, 2006. 729 p.

NERES, L. P.; CONCEIÇÃO, G. M. Florística e fitossociologia da Área de Proteção Ambiental Municipal do Inhamum, Caxias, Maranhão, Brasil. Cadernos de Geociências, Salvador, v. 7, n. 2, p. 122-130, 2010.

NÓBREGA, R. S. A.; LACERDA, A. M.; MOTTA, J. S.; MOREIRA, F. M. S. Tolerância de bactérias diazotróficas simbióticas a salinidade in vitro. Ciência e Agrotecnologia, Lavras. v. 28, n. 5, p. 899-905, 2004.

ODEE, D. W.; SUTHERLAND, J. M. ; MAKATIANI, E. T.; MCINROY, S. G.; SPRENT, J. I. Phenotypic characteristics and composition of rhizobia associated with woody legumes growing in diverse Kenyan conditions. Plant and Soil, New York, v.188, p. 65-75, 1997

OLIVEIRA, L. A. de.; MAGALHÃES, H. P. de. Quantitative evaluation of acidity tolerance of root nodule bacteria. Revista de Microbiologia, São Paulo, v. 30, p. 203-208, 1999.

RUIZ-DÍEZ, B.; FAJARDO, S.; FELIPE, M. R.; FERNÁNDEZPASCUA, M. Characterization of rhizobia from legumes of agronomic interest grown in semi-arid areas of Central Spain relates genetic differences to soil properties. Journal of Basic Microbiology, Berlin, v. 52, p. 66-78, 2012.

RUFINI, M.; FERREIRA, P. A. A.; SOARES, B. L.; OLIVEIRA, D. P.; ANDRADE, M. J. B. de; MOREIRA, F. M. de S. Simbiose de bactérias fixadoras de nitrogênio com feijoeiro-comum em diferentes valores de $\mathrm{pH}$. Pesquisa Agropecuária Brasileira, Brasília, v. 46, p. 81-88, 2011.

RUMJANEK, N. G.; MARTINS, L. M. V.; XAVIER, G. R.; NEVES, M. C. P. A fixação biológica de nitrogênio. In: FREIRE FILHO, F. R.; LIMA, J. A. A.; RIBEIRO, V. Q. (Ed.). Feijão-caupi: avanços tecnológicos. Brasília: Embrapa Informação Tecnológica, 2005. p. 280-335. 
SILVA, A. T. Diversidade de bactérias simbióticas e não simbióticas isoladas de nódulos de siratro. 2012.93 f. Dissertação (Mestrado em Agronomia - Ciência do Solo) - Universidade Federal de Lavras, Lavras. 2012.

SILVA, M. F.; SANTOS, C. E. R. S.; SOUSA, C. A.; ARAÚJO, R. S. L.; STAMFORD, N. P.; FIGUEIREDO, M. V. B. Nodulação e eficiência da fixação do $\mathrm{N}_{2}$ em feijão-caupi por efeito da taxa do inóculo. Revista Brasileira de Ciência do Solo, Viçosa, v. 36, n. 5, p. 1418-1425, 2012.

SILVA, V. N.; SILVA, L. E. S. F.; FIGUEIREDO, M. V. B.; CARVALHO, F. G.; SILVA, M. L. R. B.; SILVA, A. J. N. Caracterização e seleção de populações nativas de rizóbios de solo da região semi-árida de Pernambuco. Pesquisa Agropecuária Tropical, Goiânia, v. 37, n. 1, p. 16-21, 2007.
SOUSA, J. B.; PINHEIRO, M. S.; SILVA, L. L.; MARTINS, S. C. S.; MARTINS, C. M. Caracterização de bactérias nativas de solo do semiárido isoladas de nódulos de feijão-caupi. Enciclopédia Biosfera, Goiânia, v. 10, n. 19, p. 2797-2806, 2014.

VARGAS, M. A. T.; HUNGRIA, M. Fixação biológica do N2 na cultura da soja. In: VARGAS, M. A. T.; HUNGRIA, M. (Ed.). Biologia dos solos de cerrados. Planaltina: Empresa Brasileira de Pesquisa Agropecuária, 1997. p. 297-360.

VINCENT, J. M. A manual for the practical study of root-nodule bacteria. Oxford: Blackwell, 1970. 164 p.

ZILLI, J. E.; VALICHESKIR, R.; RUMJANEK, N. G.; SIMÕESARAÚJO, J. L.; FREIRE FILHO, F. R.; NEVES, M. C. P. Eficiência simbiótica de estirpes de Bradyrhizobium isoladas de solo do Cerrado em caupi. Pesquisa Agropecuária Brasileira, Brasília, v. 41, n. 5, p. 811-818, 2006. 